\title{
Obtaining statistical data on industrial accidents in Russia
}

\author{
Evgeny Baryshev ${ }^{1, *}$, Kseniya Shmakova ${ }^{1}$, Natalia Yakshina $^{1}$, and Maria Sergeeva ${ }^{1}$ \\ ${ }^{1}$ Ural Federal University, 19 Mira str., 620002, Ekaterinburg, Russia
}

\begin{abstract}
The article investigates the problem of industrial accidents statistical data collecting in Russian Federation. The industrial injuries concealment causes, including those with a fatal outcome, are analyzed. Possible purposes is indicated to use reliable statistics on industrial injuries.
\end{abstract}

\section{Introduction}

The problems associated with industrial injuries are relevant not only for Russia, but also for the whole world. As an industrial accidents result, a significant number of able-bodied people die or become disabled annually.

Thus, according to the International Labor Organization, more than 2.34 million people die annually as a result of work-related accidents or work-related illnesses. In addition, approximately 374 million fatal accidents and illnesses occur each year, leading to an increase in the length of absence from work. The annual economic losses associated with industrial accidents and occupational diseases are estimated at 3.94 percent of the global gross domestic product [1-2].

Despite the fact that article 37 of the Constitution of the Russian Federation stipulates that "Every citizen has the right to work in conditions that meet the requirements of safety and hygiene", according to the Federal State Statistics Service more than 47 thousand people are injured every year at work, from about 2 thousands of them die [3].

Thus, the current medical and demographic situation in Russia in a fairly short time may lead to a real shortage of labor resources.

Therefore, reducing the industrial injuries level is one of the most serious today tasks. In order to solve it effectively, it is necessary, first of all, to know the true problem extent.

According to the International Labor Organization (ILO) estimation the industrial accidents actual number is significantly higher than the official data provided by these countries authorities.

Industrial accidents number data, including fatalities, in various countries are presented in table 1.

\footnotetext{
* Corresponding author: e.e.baryshev@urfu.ru
} 
Table 1. Data on the number of accidents and deaths in various countries for 2003.

\begin{tabular}{|c|c|c|c|c|c|}
\hline Country & $\begin{array}{c}\text { Total number of } \\
\text { employees }\end{array}$ & $\begin{array}{l}\text { Fatalities } \\
\text { reported to the } \\
\text { ILO }\end{array}$ & $\begin{array}{c}\text { Accidents } \\
\text { (absence from } \\
\text { work for more } \\
\text { than } 3 \text { days), } \\
\text { according to } \\
\text { data provided to } \\
\text { the ILO }\end{array}$ & $\begin{array}{l}\text { Fatalities } \\
\text { number by } \\
\text { ILO }\end{array}$ & $\begin{array}{l}\text { The average } \\
\text { value of } \\
\text { accidents with } \\
\text { absence from } \\
\text { work } 4 \text { days, } \\
\text { according to } \\
\text { the ILO }\end{array}$ \\
\hline Finland & 2385000 & 43 & 56268 & 49 & 46068 \\
\hline France & 24630900 & 661 & 721227 & 782 & 735214 \\
\hline Estonia & 594300 & 31 & 3199 & 38 & 35849 \\
\hline Hungary & 3921900 & 133 & 25612 & 164 & 153804 \\
\hline Latvia & 1006900 & 41 & 1322 & 50 & 47413 \\
\hline Romania & 9222500 & 418 & 5552 & 1016 & 955493 \\
\hline Moldova & 1356500 & 43 & 619 & 113 & 105817 \\
\hline Russua & 66496000 & $3538^{a}$ & $-{ }^{b}$ & 5816 & 5468474 \\
\hline USA & 137736000 & 5575 & 1315920 & 6857 & 6446752 \\
\hline
\end{tabular}

Table 1 shows that some injuries and fatal cases are not recorded at work (despite the fact that fatal cases are very difficult to hide). Indeed, many domestic and foreign researchers have noted the concealment of industrial accidents, and especially injuries classified as mild [4-8].

\section{Results and discussion}

The reasons for the discrepancies in the statistics on industrial accidents can conditionally be divided into three groups. The first is related to employers, the second is to employees, the third group of reasons is related to organizations reporting accidents.

We can distinguish the following reasons for industrial accidents concealment that are associated with employers.

In accordance with art. 212 of the Russian Federation Labor Code (LC), the obligations to ensure safe working conditions and labor protection are assigned to the employer. At the same time, he is obliged to fulfill more than twenty responsibilities related to the creation and functioning of the OSH management system, including: the acquisition and issuance of special clothes, special shoes and other personal protective equipment, flushing and neutralizing agents at his own expense; taking measures to prevent emergencies, preserving the life and health of workers in such situations, training for performing work in safe methods and techniques and first aid for injured workers, instructing in labor protection, internships at the workplace and testing knowledge of labor protection requirements and etc.

Issues related to the financing of these labor activities are discussed in part 2 of article 226 of the Russian Federation Labor Code, where it is said that: "Financing of measures to improve labor conditions and labor protection by employers (with the exception of state unitary enterprises and federal institutions) is carried out in the amount of at least $0.2 \%$ of the goods production cost (works, services)". 
Thus, the activities costs related to labor protection and improving its conditions should be attributed to the costs of the organization. In this case, the labor protection measures costs within the established standards framework, the compensation costs for harmful and hazardous working conditions, as well as paid insurance contributions, are charged from the production cost (services, work). Costs that are incurred in established standards excess are paid from the organization profit.

Despite this, employers note that, firstly, they have to finance many labor protection measures from profit, because legislation does not allow them to be classified as cost. Secondly, the performing all labor protection measures costs are quite significant, which greatly affects the production cost, which means its competitiveness in the market, and accordingly, the enterprise profit.

As a result, a significant financial burden, expressed in the employer obligation to carry out numerous labor protection measures, makes it necessary to reduce their implementation costs by obtaining cheap and low-quality services. In addition, employers have problems finding certified organizations that provide equipment and work clothing that have the necessary certificates [9].

In this regard, most enterprises have serious violations in the labor protection [10]. State regulatory requirements violation for labor protection entails the administrative fine imposition from fifty to one hundred fifty thousand rubles, and if re-identified, up to two hundred thousand rubles or administrative activity suspension for up to ninety days period (Article 5.27.1 of the Russian Federation Administrative Code).

On the other hand, the penalty for concealing work-related injuries for concealing an insured event with compulsory social insurance is much lower, and provides for penalties for legal entities in the amount of 5,000 to 10,000 rubles. (Article 15.34 of the Russian Federation Administrative Code). That is why employers prefer to hide injuries at work so that the official accident investigation does not lead to additional labor protection checks, as which numerous violations result can be identified with subsequent high fines.

Also, employers prefer to hide accidents due to fear of criminal prosecution. Industrial injuries fall under two articles of the Criminal Code of the Russian Federation - article No. 143 "Violation of labor protection requirements" and article No. 216 "Violation of safety rules during construction or other works". There is a risk of up to two years in prison in a severe accident and up to seven years in a group fatal accident.

Another reason influencing the accidents concealment by employers is the current system of discounts and allowances for compulsory insurance against industrial accidents and occupational diseases. The discount size or allowance is calculated based on the insured for three years work results and is determined by the insured taking into account the state of labor protection (including the special assessment working conditions results, mandatory preliminary and periodic medical examinations) and insurance costs (Art. 22 No. 125-FL). Thus, employers with a minimum level of work-related injuries are eligible to receive discounts on the insurance rate. The employers' economic interest in lowering insurance rates has an impact on their concealment of work-related injuries.

The next reason for hiding industrial accidents is the ability to return up to $20 \%$ of the contributions listed in the Social Insurance Fund, which the employer can spend on labor protection measures. If the employer registers an accident, then the amount that can be spent on financing preventive measures is reduced.

At the end of the reasons for industrial accidents related to employers concealment review, one can single out the absence of labor contracts (agreements) providing for social protection of the employee. The reason that underestimates the statistics on the number of industrial accidents associated with workers is the latter's misunderstanding of the principles and rights to compensation for harm. In this regard, the following situations may arise when an employee does not register an industrial injury. 
Firstly, it is beneficial for the employee to take out the injury not as industrial, but as domestic, if the employer promises to compensate for the damage suffered. Moreover, in accordance with Art. 8 202-FL, a sick leave certificate for domestic injury since 2005, the employee will be paid from the first day of disability.

Secondly, the employee's fear of losing his job leads to a reluctance to file an accident at work, because his registration can lead to tensions between the employer and the employee.

Thirdly, in the industrial injuries statistics, in most cases, accidents that have occurred with illegal workers are not reflected. This problem is currently becoming urgent due to the fact that according to official data, 2 million migrants are registered in Russia, while according to the Federal Migration Service of the Russian Federation, there are about 10 million illegal migrants in the country.

If an accident at work occurs with illegal workers, then it is not recorded in magazines and not reported to the relevant authorities. Moreover, non-registered migrant workers themselves, fearing being deported, do not seek to register an accident.

Thus, the low legal literacy leads to the fact that not having information about the compensations for compulsory social insurance due to the provided by law disability case and other guarantees, makes employees agree to the employer proposal not to register a work injury.

The third group of reasons related to organizations reporting on accidents is caused by the following factors. Data on the number of industrial accidents (group, severe or fatal) are received by various ministries and departments: the Federal Service for Labor and Employment, the Social Insurance Fund of the Russian Federation, the Federal State Statistics Service, the Pension Fund of the Russian Federation and other organizations within their competencies. Но, несмотря на такой многократный статистический учет, наблюдаются разногласия в данных у различных ведомств But, despite such multiple statistics, there are disagreements in the data from various departments [11-12].

The discrepancy in information on industrial accidents using the reporting example by the Federal State Statistics Service (FSSS) and the Social Insurance Fund (FIS) is presented in Table 2 [13-14]. 
Table 2. Statistics on the number of industrial accidents in Russia according to the Federal State Statistics Service and the Social Insurance Fund.

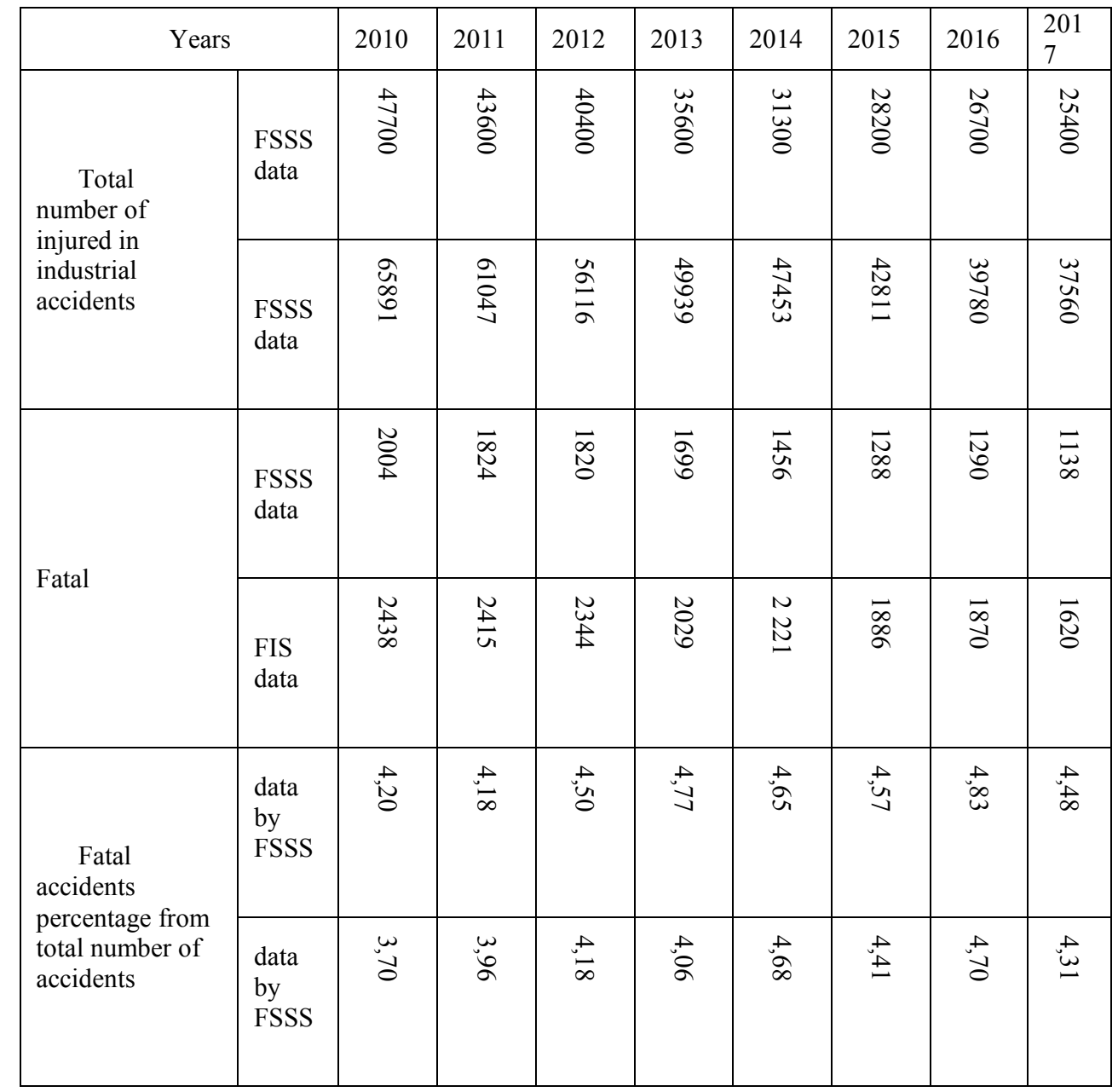

The data in table 2 shows that the fatal accidents share in the total number of industrial accidents is from 3.7 to 4.83 percent. 


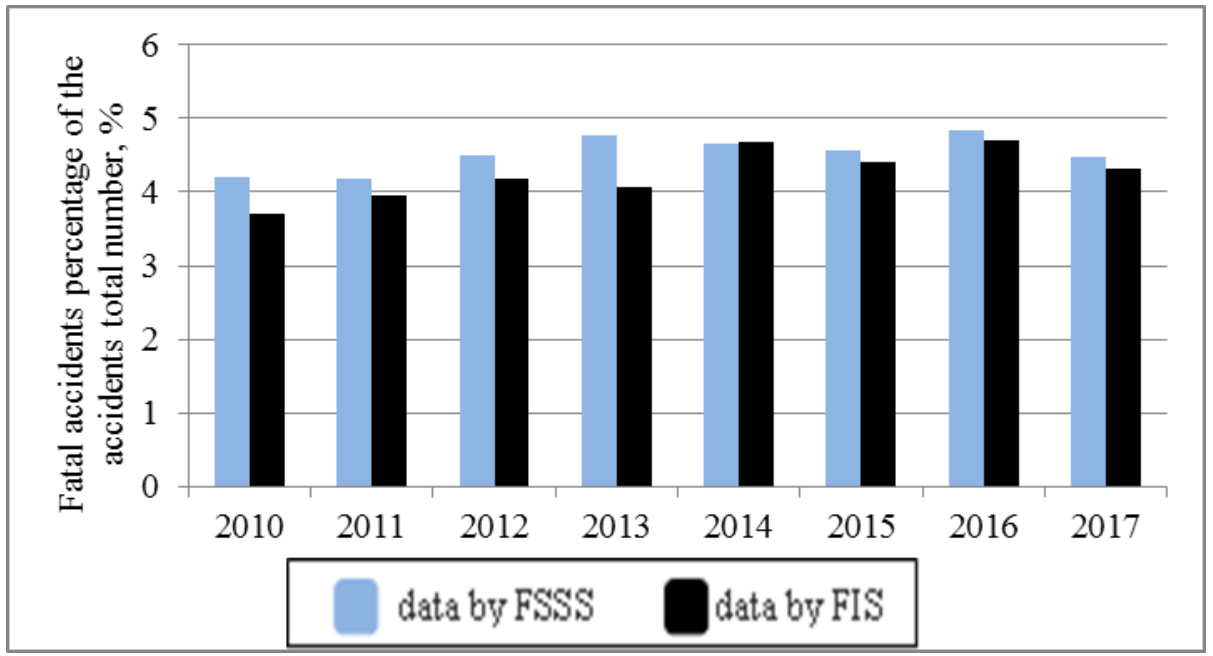

Fig. 1. The fatal accidents percentage from the total number of industrial accidents according to the data obtained by the FSSS and the FIS.

The histogram in Figure 1 shows that according to the data collected by the FSSS and the FIS the fatal accidents ratio to their total number differ only slightly (average values are 4.52 and 4.25 percent, respectively). However, according to the International Labor Organization, with an objective account of industrial accidents, this ratio should be in the range of $0.1-0.2$ percent. If we establish this ratio at the level of even one percent, then the total number of accidents in Russia should be 120,000-160,000 per year.

The inconsistency of statistics and the real situation is confirmed by ILO information, which, referring to the Government of the Russian Federation, suggests that 190 thousand people die in Russia every year due to work in dangerous conditions, 15 thousands of them as a accidents result. In addition, 180 thousand people are forced to retire ahead of schedule due to industrial accidents and occupational diseases. [15].

In studies related to the injuries federal monitoring indicators analysis, the following shortcomings are noted in the collection of statistical data by relevant organizations:

- the approved statistical indicators nomenclature does not meet the requirements necessary for the functioning of the professional risk management system;

- there is no electronic system for recording, storing and processing data on industrial injuries;

- Federal State Statistics Service statistical observations, Russian Federation Ministry of Labor and the Social Insurance Fund do not include workers professional affiliation, but characterize only the general situation at best by type of economic activity, as well as by federal districts and constituent entities of the Russian Federation;

- there is no accounting for injuries in small and micro enterprises;

- there are no statistics on microtrauma and minor injuries, first aid cases, which can subsequently be realized in an accident.

In the Ordinance on industrial injury statistics accepted at the sixteenth International Conference of Labor Statistics (October 1998), the main purpose of collecting statistical information on industrial injuries is to provide comprehensive and timely information on industrial injuries for the preventive purposes. On this basis, the statistics of industrial injuries can be used for the following tasks:

- economic activity professions and types identification where industrial injuries, along with its scope, severity and occurrence methods, are used as the basis for planning preventive measures; 
- setting priorities for preventive measures;

- identifying changes in the nature and occurrence of work-related injuries in order to monitor improved safety and identify any new areas of risk;

- informing employers, employers 'organizations, workers and workers' organizations about the risks associated with their work and workplaces so that they can take an active part in ensuring their own safety;

- preventive measures effectiveness assessment;

- work-related injuries consequences assessment, especially in terms of lost days or costs;

- providing the basis for developing policies aimed at encouraging employers, employers 'organizations, workers and workers' organizations holding events to prevent industrial accidents;

- assisting in the training materials development and accident prevention programs;

- providing a basis for identifying possible areas for future research.

\section{Conclusion}

Thus, collecting information on industrial accidents statistics is a difficult but necessary task.

This is due to the fact that, based on the industrial accidents statistics normative indicators for organizing workplaces in the production, personal protective equipment and safety equipment are developed. Also priority areas for measures to reduce the industrial accidents number are identified, planning and preventive measures implementation aimed at improving working conditions, labor protection and preserving workers health are carried out.

In addition, the state establishes restrictions for specific professions or positions by age or gender, compensation size, leave length, retirement age, working hours.

By analyzing information on industrial accidents statistics in economy various sectors, it is possible to retract the industrial injuries level by reducing the workers number in industries with a high level risk. In this case, in factories with a professional injuries high level risk, it is necessary to provide measures for organizing modern and high-quality emergency care, the ability to injured quickly transportation to medical facilities and provide them with quality treatment. This should ultimately lead to a reduction in the number of fatal accidents.

Due to this, it can be drawn the following conclusion: workers life and health preserving task implementation and therefore labor resources, requires work accidents information collection and processing clear organization by state authorities, local governments, employers and public organizations. A systemic multi-agency approach is also needed.

\section{References}

1. Prevention of occupational diseases (first edition, ILO, Moscow, 17, 2013)

2. T.L. Lukyanchikova, Labor economics, 5(3), 647-662 (2018) doi: 10.18334/et.5.3.39334

3. On the sanitary-epidemiological situation in the Russian Federation in 2010: State report (Federal Center for Hygiene and Epidemiology of Rospotrebnadzor, Moscow, 431, 2011)

4. D.A. Pilipchuk, V.M. Minko, Vestnik molodezhnoy nauki, 2 (2015) 
5. G.I. Tikhonova, A.N. Churanova, T. Gorchakova, J. Forecasting Problems, 3, 103-16 (2012)

6. A.N. Churanova, J. Occupational medicine and industrial ecology, 9, 152-3 (2015)

7. I.V. Galyanov, N.S. Studennikova, Bulletin of Rural Development and Social Policy, 2(14), 13-20 (2017)

8. A.F. Rusak, Vestnik IAELPS, 3(24), 40-43 (2019)

9. N.A. Samarskaya, Labor economics, 4(3), 209-222 (2017) doi: 10.18334/et.4.3.38310.

10. General information on the implementation of state supervision of employers' compliance with labor legislation and other regulatory legal acts containing labor law norms: report on the activities of the Federal Service for Labor and Employment for 2018 (Moscow, 187, 2019)

11. A. Bakaryagina, Vestnik molodezhnoy nauki, 2 (9) (2017)

12. E.V. Koldina, V.M. Minko, Vestnik molodezhnoy nauki, 2(2) (2015)

13. Official website of the Federal Service for Labor and Employment, URL: https://rosstat.gov.ru/working_conditions

14. Official website of the Social Insurance Fund of the Russian Federation, URL: https://fss.ru/ru/statistics/index.shtml

15. Official website of the International Labour Organization, URL: https://www.ilo.org/moscow/areas-of-work/occupational-safety-and-health/lang-$\mathrm{ru} / \mathrm{index} . \mathrm{htm}$ 